\title{
AS OPERAÇÕES DE MANUTENÇÃO DE PAZ DAS NAÇÕES UNIDAS NO INÍCIO DA DÉCADA DE 1990
}

\section{Vanessa Braga Matijascic ${ }^{1}$}

Resumo: O presente trabalho tem o objetivo de explicar o novo contexto no qual estiveram inseridas as operações de manutenção de paz das Nações Unidas entre as décadas de 1980 e 1990, e como as mudanças engendradas nesse período afetaram a solução pacífica de conflitos. A partir da observação da demanda existente e do interesse dos atores do sistema internacional, verificaremos se a transformação das operações de manutenção de paz teve implicações de origem meramente normativa ou se foi uma necessidade de dar resposta política rápida aos conflitos que emergiram. Faremos uma retomada do surgimento de tais operações e acompanharemos a sua evolução histórica, observando a publicação de documentos da Organização das Nações Unidas e as características dos mandatos aprovados pelo Conselho de Segurança.

Palavras-Chave: ONU, Operações de manutenção de paz, Transição pós-Guerra Fria.

Resumen: Este artículo pretende explicar el nuevo contexto en el que se inserta para el mantenimiento de la paz de las Naciones Unidas entre los años 1980 y 1990, y cómo los câmbios que han surgido em este período afectó a la solución pacífica de los conflictos. De la observación de la demanda existente y el interes de los actores en el sistema internacional, compruebe que la transformación de lãs operaciones de mantenimiento de la paz tiene consecuencias para las normas de origen o no era más que una necesidad política de responder rápidamente a los conflictos que surgieron. Vamos a hacer una reanudación de la subida de esas operaciones y que seguirá su desarrollo histórico, tomando nota de La publicación de los documentos de las Naciones Unidas y las características de los mandatos aprobados por el Consejo de Seguridad.

Palabras-clave: ONU, operaciones de mantenimiento de la paz, transición pos-guerra Fría.

Abstract: This paper aims to explain the new context in which they were inserted for maintenance of United Nations peace between the 1980 and 1990, and how the changes engendered in this period affected the peaceful settlement of conflicts. From the observation of existing demand and interest of actors in the international system, check that the transformation of peacekeeping operations had implications for origin rules or was merely a political need to respond quickly to conflicts that emerged. We will make a resumption of the rise of such operations and we will follow its historical development, noting the publication of documents of the United Nations and the characteristics of the mandates approved by the Security Council.

Key-words: UN, peacekeeping operations, post-Cold War transition

\footnotetext{
${ }^{1}$ Doutoranda em História pela Universidade Estadual Paulista “Júlio de Mesquita Filho” (UNESP) campus Franca (2010/2014). Mestre em Relações Internacionais pela Universidade Estadual Paulista "Júlio de Mesquita Filho" (UNESP) no Programa de Pós-Graduação em Relações Internacionais "San Tiago Dantas" (UNESP, UNICAMP e PUC-SP), quando foi bolsista CAPES/PRÓ-DEFESA (2006/2008). Integrante do Grupo de Estudos de Defesa e Segurança Internacional (GEDES/CNPq). Este trabalho é uma adaptação do primeiro capítulo da dissertação de mestrado defendida em 15/12/2008. Para entrar em contato com a autora: monalisavbm@gmail.com
} 


\section{INTRODUÇÃO}

As operações de manutenção de paz das Nações Unidas surgiram na organização com o envio de uma missão de observação militar, em junho de 1948, por ocasião do fim da guerra árabe-israelense. Contudo, foi a crise do canal de Suez, em 1956, que deu origem às características das operações de paz. Em aproximadamente sessenta anos, os cinco continentes receberam este tipo de tropas da Organização das Nações Unidas (ONU). A responsabilidade pela criação, extensão ou extinção das operações de paz cabe ao Conselho de Segurança (CS). Esse órgão é designado para tomar as medidas - pacíficas e/ou coercitivas - que julgue necessárias para a resolução do conflito.

Durante a Guerra Fria, houve o "congelamento" do CS, isto é, as rivalidades entre Estados Unidos e União Soviética impediram que o Conselho agisse em comum acordo em determinadas questões devido ao poder do veto na aprovação de resoluções. A configuração bipolar foi a maior responsável pela estagnação do envio de tropas aos conflitos regionais que geralmente se caracterizavam por conflitos entre Estados.

Após o fim da Guerra Fria, as operações de paz da ONU adquiriram tarefas mais complexas, como: oferecer assistência humanitária, organizar e promover eleições, treinar polícia local, auxiliar governos locais no fortalecimento de instituições políticas, monitorar o cumprimento dos direitos humanos e profissionalizar forças militares e policiais. Além disso, entende-se que a partir desse período houve um aumento do envio de operações de paz para conflitos intra-estatais.

Acerca da existência de arcabouço teórico para as operações de manutenção de paz (peacekeeping operations), Roland Paris (2000, p.29) afirma que nenhuma teoria das relações internacionais faz menção direta a esse mecanismo. Parte da explicação está no desencontro temporal entre o surgimento das principais teorias das relações internacionais, como o realismo e idealismo, e o posterior emprego de operações de manutenção de paz pelas Nações Unidas. Podem ser utilizados, entretanto, os pressupostos dessas primeiras teorias das relações internacionais para a análise do fenômeno. Logo, numa primeira análise, a ONU deveria colocar em prática todos os propósitos para os quais ela foi criada. Nessa perspectiva idealista, a comunidade internacional considera o organismo como grande pacificador dos conflitos que ameaçam a paz e a segurança internacionais, norteado pelas regras do direito internacional (NOGUEIRA; MESSARI 2005, passim).

Certamente, a atuação da ONU conseguiu atender à demanda das preocupações da nova agenda de segurança do início da década de noventa no século XX. No entanto, ao analisarmos o foro de decisões dessas medidas, o Conselho de 
Segurança, o paradigma tradicional das relações internacionais, a perspectiva realista, parece ser mais adequado para embasar os interesses que orientaram os membros permanentes do Conselho no veto ou na aprovação do envio de operações de manutenção de paz.

Como potências, os Estados agem sobrepondo seus interesses aos demais numa relação assimétrica de configuração de relação de forças (ARON, 1985). O objetivo dos atores estatais que são potências é projetar poder, materializando seus interesses e assegurando sua sobrevivência estatal (MORGENTHAU, 2003).

Sendo assim, a argumentação de Mearsheimer para invalidar a euforia de novas vertentes acadêmicas, que atribuíam às instituições internacionais à promoção da paz e segurança internacionais no início dos anos 1990, apresenta-se como uma defesa bem fundamentada do comportamento dos países que tinham mais poder e que também faziam parte das principais organizações internacionais. Partindo das premissas do realismo, o autor se propôs a apresentar, e depois a relativizar, as visões (liberal institucionalista, da segurança coletiva e da teoria crítica) que acreditavam que as instituições seriam as grandes responsáveis pela paz mundial no mundo pós-Guerra Fria (MEARSHEIMER, 200o, passim). Para Mearsheimer, as instituições e as questões de guerra e de paz refletem apenas a distribuição do poder mundial, isto é, refletem uma série de regras de comportamento e normas que já foram estabelecidas no momento de concepção dos organismos internacionais. Geralmente essas regras conservam a ordem internacional estabelecida. Portanto, não há como mudar um sistema internacional anárquico em que os interesses são definidos em termos de poder.

Trabalhando com essa perspectiva, e dialogando com os objetivos de natureza humanitária para os quais a ONU foi criada, encontraremos nas operações de manutenção de paz um interessante objeto de estudo para entendermos de que maneira existe a co-existência do cumprimento dos anseios coletivos da comunidade internacional e o comportamento racional das potências para materializar interesses políticos que visem à projeção de poder.

\section{O NOVO CONTEXTO}

Na transição do final da década de 1980 para o início da década de 1990, certos acontecimentos trouxeram mudanças significativas para agilizar a tomada de decisões pela ONU em ações que visavam manter a paz e a segurança internacionais.

Nesse período, percebe-se que os tradicionais conflitos entre Estados diminuíram consideravelmente, existindo apenas alguns episódios como a Guerra do 
Golfo e as disputas entre árabes e israelenses nos primeiros anos da década de 1990. Por outro lado, os conflitos oriundos de divergências de fundos étnico, político e religioso, internas aos Estados, afloraram em países em desenvolvimento. Interpretamos que, em parte, a razão para isso está relacionada ao fato de que tais conflitos estiveram estagnados durante a Guerra Fria e emergiram com mais força na transição da década de 1980 para o início dos anos 1990. Grande parte desses países havia conquistado independência nos processos de descolonização das décadas de 1960 e 1970, além daqueles que eram ex-integrantes da União Soviética. Logo, possuíam problemas de diferentes naturezas, como crises de governabilidade, instituições políticas frágeis, grupos civis armados que promoviam a violência e a violação de direitos humanos, além de recorrente instabilidade econômica que geravam e agravavam crises humanitárias.

Nas palavras do secretário-geral Boutros Boutros-Ghali (1998, p.21), em exercício no cargo de 1992 a 1997, as ações da ONU para promoção da paz e da diplomacia preventiva aumentaram em número e em variedade no pós-Guerra Fria, contabilizando 11 casos em 1988, 16 em 1992 e 30 em 1995. O secretário-geral também afirmou que houve o aumento do envio das operações de manutenção de paz: de 5 operações em 1988 para 11 em 1992, sendo grande parte dos envios destinados a mediar conflitos intra-estatais. Boutros-Ghali argumentou que tais fatores implicaram em elevação do orçamento anual da ONU: de 230 milhões de dólares em 1988 para 3,6 bilhões em 1995.

Quanto às considerações sobre as mudanças qualitativas, o secretário-geral enfatizou que grande parte dos conflitos intra-estatais envolveram forças irregulares com uma das partes em litígio, ao invés de exércitos nacionais, e que muitas fatalidades acometeram civis. Na maioria dos casos em que os conflitos apresentaram essas características, Boutros-Ghali (1998, loc. cit.) destacou que havia colapso das instituições estatais e que isso exigiria maior empenho da ONU nos novos desafios, os quais não seriam superados pelas operações de manutenção de paz tradicionais.

Nesse novo contexto, as operações de manutenção de paz da ONU seriam diversas, realizando tarefas como desmobilizar tropas, promover processos de reconciliação nacional, organizar e monitorar eleições, restaurar governos e prover assistência econômica e social em longo prazo para a reconstrução de países. Os esforços da ONU para promover a paz seriam mais dispendiosos financeiramente e deveriam estar preparados para atuar em conflitos de natureza mais complexa e com elevado grau de perigo para o efetivo de tropas e funcionários das Nações Unidas que operasse em campo. Nesse sentido, o secretário-geral salientou que foi necessário que a ONU atuasse em cooperação com outros atores internacionais para que fosse possível 
realizar todas as atividades desejadas que trouxessem segurança e estabilidade para os Estados que passavam por tais adversidades.

\section{REGIÕES INSTÁVEIS}

As operações de manutenção de paz enviadas entre os anos de 1988 e 1996 tiveram majoritariamente três destinos: países africanos, países do leste europeu e países da América Central e do Caribe (BOBROW; BOYER 1998, p.731). Geralmente, as operações de manutenção de paz enviadas para países africanos como Angola, Namíbia, Somália, Moçambique, Uganda, Ruanda e Libéria, mediaram conflitos em sua maioria intra-estatais nos quais as disputas tinham origem nas rivalidades entre grupos políticos ou clãs e etnias diferentes que habitavam o mesmo território. Esses conflitos desencadearam fluxos migratórios de pessoas que fugiam da violência, da pobreza e das violações de direitos humanos, ocasionando instabilidades regionais com os países vizinhos (DEPARTAMENTO DE INFORMAÇÃO PÚBLICA DAS NAÇÕES UNIDAS, 1995, p.33-56).

Por um lado, os conflitos que existiram no leste europeu foram oriundos do processo de desintegração da ex-Iugoslávia, por povos que tinham o interesse de se desvincular da antiga federação e proclamar independência política. E por outro, do desejo sérvio de manter a unidade territorial. As disputas pela emancipação desses povos resultaram em conflitos armados com o exército iugoslavo, principalmente após 1991, quando Croácia e Eslovênia se declararam independentes, sendo que, em 1992, a Bósnia-Herzegovina e, em 1993, a Macedônia adotaram a mesma conduta. Disputas armadas pela conquista da independência e confrontos que desrespeitaram os direitos humanos causaram instabilidade na região. Nesse sentido, as operações de manutenção da paz enviadas pela ONU tinham o intuito de fazer com que as partes negociassem para que a paz fosse alcançada, além de tentar promover o desarmamento das partes em conflito, a proteção dos civis e a viabilização da entrega de ajuda humanitária (DEPARTAMENTO DE INFORMAÇÃO PÚBLICA DAS NAÇÕES UNIDAS 1995, p.113119).

América Central e Caribe eram regiões que também integraram outro foco de alerta para a ONU, pois diversos países passavam por processos tumultuados de transição política de regimes autoritários (com graves crises de representatividade política) a democráticos. Zelando para promover a estabilidade nesses locais e a completude de tais transições, ONU e Organização dos Estados Americanos (OEA) trabalharam juntas para que Nicarágua, El Salvador, Guatemala e Haiti alcançassem 
estabilidade democrática e fomentassem a desmobilização de grupos civis armados nocivos ao cumprimento dos objetivos aqui destacados.

\section{AS OPERAÇõES DE MANUTENÇÃO DE PAZ DAS NAÇÕES UNIDAS}

As operações de manutenção de paz são mecanismos das Nações Unidas para manter, impor ou alcançar a paz em regiões de conflito. São ações autorizadas pelo Conselho de Segurança (CS) e que surgiram historicamente com composição estritamente militar, mas, ao longo dos anos, adquiriram composição mais complexa, somando civis e policiais ao seu contingente.

É verdade que estas operações de manutenção de paz podem desenvolver funções de mediação ou conciliação em certos casos concretos, como por exemplo, para deter confrontos armados entre as partes do conflito, e também podem participar nas negociações de um cessar-fogo ou em processo de desmobilização e desarmamento de uma das partes conflitantes, mas seu mandato nunca é resolver a diferença política, de modo que nem são em si medidas para a resolução pacífica de conflitos do Capítulo VI da Carta, nem se dedicam a desenvolver as funções ali descritas (UNCETA 2005, p.123-4).

O CS aprova o mandato das operações de manutenção de paz e é informado pelo relatório da Secretaria Geral das Nações Unidas (SGNU) sobre o andamento das operações. Cabe à Assembléia Geral votar o orçamento e ao Departamento de Operações de Manutenção de Paz prover a logística e o apoio material necessários ao desempenho das atribuições, bem como o treinamento e as orientações a militares e policiais enviados à região de conflito.

\section{ORIGEM HISTÓRICA, PRINCÍPIOS E CARACTERÍSTICAS}

O primeiro registro de operações de paz adotado por organismos intergovernamentais no século XX é o da Liga das Nações (1919-1934). Nas décadas de 1920 e 1930, essas operações de paz foram empregadas para prevenir conflitos entre Estados e manter a paz no sistema internacional (FONTOURA, 1999, p.47).

Com o surgimento da ONU, em 1945, as questões referentes à manutenção da paz e da segurança internacionais ganharam destaque na Carta das Nações Unidas. Em 1956, a Assembléia Geral aprovou a Primeira Força Emergencial das Nações Unidas (FENU I) para solucionar a crise do Canal de Suez². Além de enviar tal força, a

\footnotetext{
2 A Crise do Canal de Suez (1956) teve início com a nacionalização do Canal pela ação militar do governante
} egípcio general Gamal Abdel Nasser. Este líder, ao nacionalizar o Canal, impediu que Israel, França e 
Assembléia Geral foi responsável por elaborar os princípios norteadores que guiaram os contingentes militares para cumprir o mandato estabelecido pela ONU, a partir da observação de práticas que facilitariam o trabalho das Nações Unidas para solucionar a crise. Entre os fundamentos estavam o consentimento das partes, a imparcialidade, a neutralidade, a participação voluntária e o uso restrito da força. Tais princípios compuseram o marco que norteou as demais operações de manutenção da paz enviadas pelas Nações Unidas para a resolução de conflitos entre Estados e intra-estatais.

O princípio do consentimento das partes fez com que a ONU realizasse uma consulta prévia aos atores envolvidos no conflito sobre o envio e a composição de tropas de forças de paz das Nações Unidas. O consentimento consistiu no comum acordo entre os envolvidos no litígio para receber tropas, bem como na concordância quanto à composição militar das mesmas (CARDOSO, 1998, p. 20). Sobre a imparcialidade nas operações de manutenção de paz, é um fundamento diretamente relacionado ao cumprimento do mandato de forma objetiva, sem privilegiar qualquer uma das partes em contenda. Com essa diretriz, a ONU almejou obter êxito mediando conflitos com total isenção (CARDOSO, 1998, p.21).

Durante a Guerra Fria, o CS teve cautela ao elaborar projetos de resolução para aprovar o envio de operações de manutenção de paz. A ONU não desejava que a comunidade internacional interpretasse que essas operações fossem vistas como a extensão do conflito entre as duas grandes potências, Estados Unidos e União Soviética, em disputas militares regionais. Pensando nisso, o princípio da neutralidade surgiu como postura norteadora de isenção das posições políticas no teatro de operações. O contingente militar das operações de manutenção de paz das Nações Unidas deveria cooperar entre si, evitando defender interesses estatais durante a execução do mandato. Conseqüentemente, configurada para atuar como força apaziguadora e neutra, as operações de paz alcançaram êxito mais rápido nos processos de negociação que visavam pôr fim ao conflito (CARDOSO, 1998, passim).

Outro fundamento importante é a participação voluntária de Estadosmembros ao comporem tropas para o envio de operações de manutenção de paz, pois esses países deverem estar cientes de que devem arcar com as despesas do próprio contingente militar. Logo, ainda no momento de concepção desse mecanismo pacificador, não estava previsto o reembolso dos gastos militares pela ONU.

A SGNU, em sintonia com o CS, deveria distribuir eqüitativamente tropas, buscando contemplar a distribuição geográfica do mundo de forma proporcional nas operações de manutenção de paz. Assim, o caráter multinacional da composição de

Inglaterra utilizassem a passagem, o que e causou crise no Oriente Médio envolvendo países de fora da região, como os Estados Unidos e a União Soviética. Disponível em:

http://cpdoc.fgv.br/producao/dossies/JK/artigos/PoliticaExterna/CanalSuez Acesso em 13/11/2010. 
tropas militares seria assegurado. Essa foi uma das principais características das operações de manutenção de paz, cujo marco histórico foi o entorno das discussões do Comitê Especial sobre Operações de Paz em 1965. Tal comitê foi o responsável por definir a necessidade do caráter multinacional das tropas (CARDOSO, 1998, p.25).

Por último, o uso restrito da força foi o princípio no qual os soldados das operações de manutenção de paz da ONU deveriam pautar-se e que autorizava o soldado a fazer uso da força somente em caso de legítima defesa. Naquele momento, a ONU julgou esse princípio como fundamental para que os soldados das operações de manutenção de paz, conhecidos como soldados da paz ou peacekeepers, conquistassem a confiança e a cooperação da população local, além das partes envolvidas no conflito.

A ONU também optou pelo emprego de armamentos leves ou de "baixa" letalidade por parte dos soldados das operações de manutenção de paz em regiões de conflito (CARDOSO, 1998, p.28). Entende-se por armamento leve ou de "baixa" letalidade aquele que não é utilizado em guerras ou em situações de combate com alto potencial ofensivo, mas que serve para que o soldado da ONU se defenda em situações que lhe proporcionem risco de perda de vida. O resultado esperado com o uso da força somente em legítima defesa e da opção pelo armamento leve era causar impacto psicológico positivo nas populações em locais de contendas, para que assim colaborassem com as operações de manutenção de paz, percebendo-as como mediadoras, e não como terceira parte beligerante.

\section{AS OPERAÇÕES DE MANUTENÇÃO DE PAZ NO CONTEXTO DE TRANSIÇÃO PARA O PÓS-GUERRA FRIA}

No período bipolar do século XX (ARON, 2002), a ONU enviou operações de manutenção de paz e missões de observação às regiões de conflito. O primeiro tipo, cujo marco inaugural é a Força Emergencial das Nações Unidas, FENU I (1956-1967), teve por objetivo "supervisionar o cessar-fogo após a crise do Canal de Suez e a retirada de tropas francesas, israelenses e britânicas do território egípcio" (FONTOURA, 1999, p.66). Após a retirada dessas tropas, a FENU I foi responsável por "separar as forças egípcias e israelenses por meio de zona desmilitarizada" (FONTOURA, loc. cit.) o que a caracterizou como operação de manutenção de paz aprovada para solucionar pacificamente o conflito entre Estados. Já as missões de observação foram experiências de monitoramento militar de fronteiras entre Estados e precederam as operações de manutenção de paz.

Como exemplo de missão de observação, em 1948, o CS aprovou uma para supervisionar a trégua após o fim da guerra árabe-israelense, conhecida como 
Observação Militar das Nações Unidas para Supervisionar Trégua, cuja sigla em inglês corresponde a UNTSO. A outra operação de grupo de observadores militares das Nações Unidas, Missão de Observação Militar das Nações Unidas entre Índia e Paquistão, é reconhecida pela sigla em inglês UNMOGIP e ocorreu na fronteira entre ambos os países em $1949^{3}$.

Ao longo da Guerra Fria, as operações de manutenção de paz das Nações Unidas e as missões de observação militar caracterizaram-se, sobretudo, por atuar em conflitos entre dois ou mais Estados (conflitos interestatais). A composição dessas operações era predominantemente militar. Suas principais funções e objetivos eram manter o cessar-fogo, supervisionar tréguas, patrulhar e preservar zonas de isolamento das partes em conflito, conhecidas também como "zonas tampão" ou zonas de exclusão militar. Ademais dessas atribuições, e quando fosse possível, também deveriam empenhar-se para que as partes em conflito assinassem acordos de paz (FONTOURA, 1999, p.66-7).

A partir da aproximação do fim do período bipolar, nota-se que tais características e princípios das operações de manutenção de paz evoluíram de acordo com a necessidade da ONU em adaptar-se à natureza dos novos conflitos que emergiam ao final da década de 1980 e início da década de 1990. Nesse momento de transição, se observa o aumento na quantidade de conflitos internos ao Estado, localizados em diversas regiões do mundo. Essa elevação refletiu as conseqüências da transição do sistema internacional de configuração de relações de forças bipolar para o novo contexto do sistema internacional no término da Guerra Fria4.

No período bipolar, a configuração da relação de forças dividiu os Estados em torno dos Estados Unidos ou da União Soviética. Este momento caracterizou-se pelo esforço de contenção de contenciosos bélicos, cujo desenvolvimento em escala mundial levaria ao embate armado e direto das duas potências. Assim, os conflitos intra-estatais ficaram estagnados. Com o fim deste sistema bipolar, que teve como marco a queda do muro de Berlim, em 1989, e o fim da União Soviética, em 1991, antigas hostilidades, arrefecidas entre 1945 e 1991, emergiram.

\footnotetext{
3 Lista de operações de manutenção da paz das Nações Unidas disponível em: < http://www.un.org/en/peacekeeping/list.shtml >. Acesso em:14/11/2010.

4 Raymond Aron (2002), na obra Paz e Guerra entre as Nações, dedica o capítulo V para a definição de sistemas internacionais de natureza bipolar e pluripolar. Este se caracteriza pela existência de vários pólos de poder em que a configuração de relação de forças entre as unidades políticas mais poderosas (potências) tende a conduzir o sistema internacional a um equilíbrio. Conseqüentemente, há baixa probabilidade de eclosão de guerras. Aron sugere (como exemplo dessa situação) o equilíbrio da balança de poder entre potências européias no final do século XIX. Sobre a conjuntura bipolar, Aron persuade o leitor ao entendimento de que há uma configuração da relação de forças em que unidades políticas agrupam-se em torno de dois pólos de poder. Assim, a segurança é garantida pelo Estado mais poderoso aos demais, enquanto estes oferecem apoio financeiro e/ou político àquele. Para exemplificar essa situação, o sociólogo francês refere-se à análise da Guerra Fria e ao apoio político que os países deram aos Estados Unidos ou à União Soviética.
} 
Esse foi o entendimento das províncias que queriam se separar da exIugoslávia, como são os exemplos da Croácia e Bósnia-Herzegovina no leste europeu, e em outros países que desejavam se dissociar do domínio da ex-União Soviética.

Para Paulo Roberto Campos Tarrisse da Fontoura (1999, p. 84), a distensão política entre Estados Unidos e União Soviética teve impacto significativo sobre a ONU em questões relativas à paz e à segurança internacionais. Para ele, o contexto pósGuerra Fria aflorou antagonismos étnicos e religiosos e universalizou valores como democracia e direitos humanos, e foram esses fatores os responsáveis pelo aumento do número de operações de manutenção de paz.

De fato, a descrição de Fontoura é uma síntese das demandas que a ONU observava no início dos anos 1990. Mais precisamente, a SGNU e o CS deveriam estar atentos às causas que poderiam contribuir para a eclosão de conflitos em escala mundial, buscando realizar ações que assegurassem a manutenção da paz e da segurança internacionais.

Entre os anos de 1948 e 1989, os mandatos aprovados pelo CS para autorizar o envio de operações de manutenção de paz totalizaram um número de 18 participações. Já ao longo da década de 1990 foram aprovados 35 mandatos, sendo que 24 operações de manutenção de paz foram enviadas entre os anos de 1989 e $1995^{5}$. Portanto, neste período o CS quintuplicou a aprovação de resoluções e triplicou o envio de operações de manutenção de paz.

A ONU também exigiu que a logística e o treinamento dessas operações fossem aperfeiçoados. Em 1992 foi criado o departamento de operações de manutenção de paz da ONU, conhecido pelas siglas DPKO (Department of Peace-keeping Operations), subordinado à Secretaria Geral. Originalmente esse departamento teve como função treinar os contingentes militares e policiais e preparar os civis que atuariam em operações de manutenção de paz da ONU. Além desta atribuição, o DPKO ficaria responsável por preparar a logística e prover o apoio financeiro destinado às atividades das operações de manutenção de paz, após a Assembléia Geral aprovar o orçamento adequado a cada uma ${ }^{6}$.

O fim do período bipolar também trouxe mudanças para o CS. Anteriormente, muitas resoluções haviam sido vetadas, 279 (UMA AGENDA PARA A PAZ, 1992, parágrafo 14), em virtude das decisões dos Estados Unidos ou da União Soviética e da mútua rivalidade entre ambos. Neste novo contexto, não havia mais vetos daquela

\footnotetext{
5 Informações quantificadas a partir dos dados disponíveis na Lista de Operações de Manutenção de Paz do Departamento de Operações de Manutenção de Paz das Nações Unidas.

${ }^{6} \mathrm{O}$ envio de operações de manutenção da paz era uma proposta aprovada pelo Conselho de Segurança e examinada pela Secretaria Geral. Por sua vez, esta encaminhava a decisão do Conselho de Segurança à Assembléia Geral para que o orçamento fosse aprovado. Mediante esta aprovação, a Secretaria Geral enviava um pedido para que o DPKO preparasse a logística e o treinamento das operações.
} 
natureza, isso contribuindo significativamente para o aumento do envio de operações de manutenção de paz e para a reflexão sobre o papel do CS no pós-Guerra Fria:

A proliferação das operações de manutenção da paz ocorreu simultaneamente com a expansão do escopo da atuação do Conselho de Segurança. O CSNU passou a adotar critérios cada vez mais elásticos para definir o que constitui uma ameaça à paz e à segurança, visto que, nos anos 90, a quase totalidade dos conflitos em que as Nações Unidas têm intervindo é de natureza interna (FONTOURA 1999, p.83).

Na citação acima, Paulo Roberto Tarrisse da Fontoura menciona "critérios (...) elásticos" para referir-se à ampliação da agenda de segurança, a qual incluiu a adesão de novos temas a serem debatidos pelo Conselho, como crises humanitárias geradas por catástrofes naturais e/ou desrespeito aos direitos humanos, terrorismo, proliferação de armas de destruição em massa e falências estatais. No mundo pósGuerra Fria, as ameaças à paz e à segurança internacionais seriam diversas e, na interpretação da ONU, o CS deveria estar apto a discutir e deliberar resoluções que mantivessem a paz e a segurança no sistema internacional diante das ameaças da nova ordem internacional.

O documento que formaliza esse posicionamento da ONU é o "Uma Agenda para a Paz”, apresentado pelo então secretário-geral em exercício, Boutros BoutrosGhali, em 17 de junho de 1992. O documento menciona que a "barreira ideológica das últimas décadas" fez crescer antagonismos étnicos, sociais, culturais, religiosos e até mesmo lingüísticos. Acrescentou a isso a preocupação com as armas de destruição em massa, o racismo, os danos ambientais, o desrespeito aos direitos humanos e a fragilidade das instituições políticas de alguns Estados que seriam "forças em potencial” prejudiciais à segurança internacional (parágrafo 8). Segundo BoutrosGhali, as causas que levariam à insegurança no mundo seriam ainda mais "devastadoras" e diversas. Entre elas estariam o crescimento "exacerbado" da população mundial, o grande número de refugiados7, a pobreza, epidemias e mais uma série de ameaças a serem observadas para que atitudes eficientes fossem tomadas pela ONU para conter a emergência de conflitos, e atuar adequadamente nos já existentes.

Após identificar as mudanças no contexto internacional e as novas ameaças, o secretário-geral recomendou práticas a serem aplicadas pela ONU para conter e solucionar os conflitos dessa nova magnitude, as quais podem ser resumidas em diplomacia preventiva, peacemaking, peacekeeping, post-conflict peace-building e peace-enforcement.

\footnotetext{
7 Na definição do Alto Comissariado das Nações Unidas para os Refugiados (ACNUR) refugiados são: "pessoas comuns que foram forçadas a abandonar a sua terra para fugirem das guerras, perseguições e violações de direitos humanos". Disponível em: <http://www.cidadevirtual.pt/acnur/index.html>. Acesso em 24/07/2010.
} 
À diplomacia caberia resolver hostilidades pela via da negociação e de forma preventiva, visando a que o conflito não atingisse proporções mais graves do que as identificadas, ou que sequer chegasse a ocorrer (parágrafo 20). O peacemaking é definido como a "ação para fazer as partes em conflito chegarem a um acordo, essencialmente por meios pacíficos como aqueles previstos no Capítulo VI da Carta das Nações Unidas”. Logo, compreende ações baseadas em mecanismos pacíficos de solução de controvérsias, como negociação, mediação, solução judicial e arbitragem. Nesses casos, o CS pode ser requisitado para facilitar o processo que leva os atores envolvidos na disputa a selarem um pacto de paz. Por último, a definição para operações de manutenção de paz:

(...) é o desembarque das Nações Unidas na região em conflito, com o consentimento das partes, composta por pessoal das Nações Unidas como militares, policiais e civis. Peace-keeping é o mecanismo para expandir as possibilidades para prevenir conflitos e realizar a paz (UMA AGENDA PARA A PAZ 1992, parágrafo 20).

Nesses termos, "Uma Agenda para a Paz" determina a principal diferença nas características das operações de manutenção de paz da década de 1990, comparadas àquelas que as precederam. A distinção está na composição diversificada, pois incluiu policiais, diplomatas e civis ao tradicional contingente militar para responder adequadamente à complexidade dos conflitos.

Ainda no referido documento do secretário-geral, como medida preventiva para atuar em conflitos em que as operações de manutenção de paz não fossem suficientes para estabilizá-los, Boutros-Ghali sugeriu o peace-enforcement:

(...) forças (...) para responder a agressões eminentes ou atuais (...) em que as Nações Unidas (...) seja chamada para enviar forças para restaurar ou manter cessar-fogos (...). Consistiria em tropas voluntárias para tal serviço. Elas poderiam adotar armamentos mais pesados do que aqueles utilizados em operações de manutenção da paz (...) e atuariam sob artigo 40 da Carta ${ }^{8}$.

Boutros Boutros-Ghali sugere que o peace-enforcement seja o desembarque de tropas da ONU autorizadas a usar a força para cessar hostilidades, buscando prevenir a escalada do conflito e dar proteção militar a ações de assistência humanitária. O peaceenforcement, ou operações de imposição da paz, teria mandatos aprovados mediante Capítulo VII da Carta e atuaria sob a supervisão da Secretaria Geral.

\footnotetext{
${ }^{8}$ Grifo nosso. Parágrafo 44. O documento remete ao artigo 40 do Capítulo VII da Carta das Nações Unidas que dispõe de ordenamentos jurídicos que autorizam o CS a aprovar mandatos com a autorização do uso da força.
} 
Por fim, o post-conflict peace-building foi descrito no documento como "ação para identificar e apoiar estruturas que tenderão a fortalecer e solidificar a paz no intuito de prevenir o retorno do conflito" (parágrafo, 21). O peace-building abrange o apoio a estruturas locais que promovam o desenvolvimento econômico e social, a defesa dos direitos humanos e o fortalecimento das instituições democráticas. São ações que cooperam para o desenvolvimento de uma atmosfera pacífica em regiões pósconflito, buscando realizar projetos que impeçam a reincidência dos problemas.

As ações descritas em "Uma Agenda Para a Paz" nos levam a visualizar uma complexa gama de atuação da ONU. Após analisar os mandatos que foram aprovados pelo CS nesse período, podemos elencar as principais atribuições das operações de manutenção de paz da década de 1990, as quais estão consignadas no quadro a seguir.

\section{Mandatos das operações de manutenção de paz da década de 1990}

Objetivos das operações de manutenção de paz da década de 1990

- restaurar ou instaurar um ambiente seguro;

- reagrupar e desmobilizar exércitos irregulares, focando na reintegração desses indivíduos à vida civil e destruindo suas armas;

- repatriar refugiados;

- prover assistência humanitária;

- supervisionar estruturas administrativas;

- criar novas forças policiais;

- modernizar forças armadas;

- remover minas terrestres;

- verificar o respeito aos direitos humanos;

- desenvolver e supervisionar reformas constitucionais, judiciais e eleitorais;

- monitorar a organização de eleições;

- desenvolver e coordenar projetos que possibilitem a reabilitação econômica e a reconstrução da infra-estrutura de países destruídos por guerras civis.

*As operações de manutenção de paz das Nações Unidas.

FONTE: Departamento de Operações de Manutenção de Paz.

Disponível em: < http://www.un.org/Depts/dpko/dpko/>. Acesso em: 24/o7/2010.

Além da composição multidisciplinar, foi imprescindível o envolvimento de outros atores internacionais para que as operações de manutenção de paz cumprissem adequadamente os mandatos. Entre os envolvidos estão as agências da ONU como o Alto Comissariado das Nações Unidas para os Refugiados (ACNUR), o Programa das Nações Unidas para o Desenvolvimento (PNUD) e outros organismos, como agências regionais de cooperação econômica, organizações não-governamentais e voluntários das Nações Unidas. 


\title{
OS DESAFIOS DOS CONFLITOS INTRA-ESTATAIS PARA A ONU
}

"Uma Agenda para a Paz" assinalava que os conflitos do contexto pós-Guerra Fria apresentavam uma natureza mais complexa, e que poderiam oferecer mais riscos às tropas das operações de manutenção de paz do que aqueles observados no período bipolar. Assim, a ONU ampliou o escopo de atuação, discernindo o conjunto de ameaças a serem enfrentadas pelo CS.

Além da ampliação da agenda de segurança, como conseqüência da definição das novas ameaças, a ONU encontraria desafios em determinados tipos de conflito:

\begin{abstract}
Nos conflitos inter-estatais, o consentimento é dado por partes claramente identificáveis, que controlam seus territórios, havendo, portanto, interlocutores para negociar e buscar soluções para questões específicas. Nos conflitos intra-estatais, por outro lado, o consentimento é bastante menos estável, na medida em que é difícil identificar interlocutores com capacidade de expressá-lo, ou se expresso, de implementá-lo (FONTOURA, 1999, p.97).
\end{abstract}

Em princípios dos anos 1990, combater as causas dos conflitos intra-estatais era um grande desafio para a ONU. Algumas das partes envolvidas nesses conflitos, por exemplo, poderiam não ser tão facilmente identificáveis: “exércitos irregulares”, grupos civis armados, atores não-estatais armados (FRANCO, 1998, p.117). Muitos desses grupos agiam ilegal e clandestinamente, e não poderiam ser reconhecidos pela ONU como partes do conflito porque não eram atores políticos.

Entretanto, a ONU poderia considerá-los como ameaça interna à estabilidade e à segurança de um Estado, o qual, na medida em que não conseguisse mais gerir seus problemas internos de forma auto-suficiente, poderia solicitar o auxílio da ONU para solucionar a crise interna9. Assim, quando houvesse o pedido do país hóspede, e se os membros do CS interpretassem que tais circunstâncias representavam ameaça à paz e à segurança internacionais, o CS poderia aprovar o envio da operação de manutenção de paz para atuar nesse tipo de conflito.

Por outro lado, caso não houvesse a solicitação do país hóspede, a ONU poderia enviar operações de imposição da paz. "Uma Agenda para a Paz" dá essa possibilidade de ação quando define o peace-enforcement. Nesse sentido, o uso da força seria uma forma de procurar cessar hostilidades e oferecer assistência

\footnotetext{
9 Esse assunto é polêmico pelo fato de a ONU não ser um instrumento de solução de crises internas. No entanto, em alguns casos, como no Haiti em 1993, a aprovação para o envio da operação de manutenção de paz foi importante para conter os fluxos migratórios inconvenientes aos países vizinhos e para restabelecer a ordem interna e prevenir a escalada do conflito para a República Dominicana. Tal conjuntura é perceptível nas considerações da Comissão Interamericana de Direitos Humanos sobre os fluxos migratórios haitianos e a crise política no país. Disponível em: <http://www.cidh.oas.org/countryrep/EnHa93/annexes.htm>. Acesso em: 13/11/2010.
} 
humanitária para populações que sofriam sérias violações de direitos humanos e privações de condições mínimas para a sobrevivência. Devemos recordar que as violações mencionadas deveriam constituir ameaça à paz e à segurança internacionais nos termos do documento "Uma Agenda para a Paz".

Notamos que o consentimento das partes, o não-uso da força e a neutralidade são princípios que poderiam não ser imperativos quando o CS interpretasse que a defesa de causas humanitárias fosse uma variável de maior relevância e, em decorrência de tal apontamento, aprovasse operações de imposição de paz.

Ao observamos os mandatos das operações de manutenção de paz dos três primeiros anos da década de 1990 que foram enviadas para mediar conflitos intraestatais, percebemos a manutenção dos cinco princípios originais das operações do período bipolar: consentimento das partes, imparcialidade, neutralidade, participação voluntária e uso restrito da força. Porém, algumas dificuldades fizeram com que a ONU refletisse sobre a preservação desses princípios.

Devemos destacar que em alguns conflitos intra-estatais o não-uso da força poderia representar séria ameaça à segurança dos enviados das Nações Unidas. Tal fato chegou a acontecer na Somália em 1993, quando o mandato da UNOSOM I (sigla pela qual é conhecida a primeira operação de manutenção de paz enviada para o país) não previa o uso da força. Nos dias 04 e 05 de outubro de 1993, imagens transmitidas em cadeia mundial de televisão pela Cable News Network (CNN) mostraram corpos de soldados norte-americanos, que integravam a operação de manutenção de paz da ONU, sendo carregados por uma das partes envolvidas no conflito pelas ruas da capital da Somália, Mogadíscio ${ }^{10}$. A repercussão das imagens trouxe o questionamento à comunidade internacional quanto à preservação do princípio do não-uso da força em contendas que representavam grande ameaça à segurança dos enviados das Nações Unidas. Posteriormente, o mesmo princípio foi questionado quanto à deficiência da ONU em conter a escalada do contencioso em Ruanda, em 1994. Neste caso, a operação de manutenção de paz não conseguiu conter o embate entre grupos étnicos rivais hutos e tutsis e, para preservar a segurança dos funcionários e enviados da ONU, o CS deliberou que a operação de manutenção de paz fosse retirada do país.

Somado ao fato de a credibilidade da ONU estar abalada nesses anos, o aumento no envio de operações de manutenção de paz também elevou o orçamento da organização de aproximadamente 230 milhões de dólares, em janeiro de 1988, para cerca de 3,6 bilhões de dólares, em dezembro de 1994 (DOYLE, 1998, p.2). As conseqüências da elevação do orçamento colocaram a ONU em grave crise financeira, em 1995. O aumento do envio de operações era conseqüência da ampliação da agenda

${ }^{10}$ A informação sobre a exibição das imagens está disponível em:

<http://www.ajr.org/Article.asp?id=1579>. Acesso em 13/11/2010. 
de segurança; logo, já era de se esperar que o orçamento se elevasse. Todavia, não estava previsto que a complexidade dos conflitos intra-estatais exigiria a permanência das tropas da ONU por períodos superiores a seis meses ${ }^{11}$.

Diante de todos esses fatores, o secretário-geral divulgou o "Suplemento de Uma Agenda para a Paz" em 1995. No documento, Boutros Boutros-Ghali enfatiza que a ONU permaneceria desempenhando o seu papel na resolução dos conflitos do pósGuerra Fria. Porém, destaca que as operações de manutenção de paz seriam adaptadas às condições de hostilidade em que o contingente militar fosse atuar baseado nas dificuldades observadas em algumas operações. Boutros Boutros-Ghali admite que certos conflitos intra-estatais apresentavam alto grau de periculosidade, semelhantes àquele em que a ONU se deparou no Congo durante a década de 1960 (parágrafo 12). Para obter êxito nesta dimensão de conflito, o CS deveria agir como procedeu no Congo, ou seja, autorizando o uso da força aos soldados da operação de manutenção de paz $^{12}$.

O consentimento das partes envolvidas no conflito foi um princípio preservado para as operações de manutenção de paz da década de 1990. Entretanto, em "Suplemento de Uma Agenda para a Paz", o secretário-geral relembra que o recrudescimento do conflito poderia obrigar o CS a agir sem o consentimento de uma das partes, principalmente quando uma delas fosse um "exército irregular" ou uma "milícia armada" (parárafo 12).

Além desse aspecto, o documento retoma os exemplos bem sucedidos de operações de imposição de paz ou peace-enforcement. O consentimento das partes envolvidas no conflito não seria necessário quando a proteção militar para ações de intervenção humanitária fosse prioridade. Como exemplo, o "Suplemento de Uma Agenda para a Paz" cita os casos das operações de manutenção de paz na BósniaHerzegovina e na Somália, ambas em 1994, em que o cessar-fogo forçado foi acompanhado de ações humanitárias.

O princípio da imparcialidade manteve-se imprescindível para o cumprimento dos mandatos nas operações de manutenção de paz da década de 1990. Entretanto, o secretário-geral afirmou que tal princípio poderia ser relativizado quando fosse de entendimento do CS. A aprovação de mandatos com o consentimento do uso da força contra umas das partes poderia ocorrer se isso facilitasse a resolução do conflito. Por fim, de todas as explanações do documento de 1995, o que realmente foi um marco que

11 Os mandatos das operações de manutenção de paz eram bastante pontuais. Para cumpri-los, convencionou-se a tradicional meta dos seis meses, mas esse tempo mostrou não ser suficiente para os conflitos de natureza interna ao Estado (FONTOURA, 1999; CARDOSO, 1998; UNCETA, 1995).

$12 \mathrm{O}$ mandato está disponível em: <http://www.un.org/depts/DPKO/Missions/onucM.htm>. Acesso em 24/07/2008. 
diferenciou as operações de manutenção de paz do período bipolar daquelas da década de 1990 foi a expressa permissão para o uso da força.

Entretanto, Boutros Boutros-Ghali não relativizaou totalmente os princípios das operações de manutenção de paz:

(...) os últimos anos têm confirmado que o respeito por certos princípios das operações de manutenção da paz são essenciais para o sucesso das mesmas. Particularmente, os três princípios mais importantes são o consentimento das partes, a imparcialidade e o não-uso da força exceto para auto-defesa (SUPLEMENTO DE UMA AGENDA PARA A PAZ, 1995, parágrafo 33).

Apesar de enunciar que o princípio do uso limitado da força seria fundamental para as operações de manutenção de paz, ao longo de todo o "Suplemento de Uma Agenda para a Paz" o secretário-geral afirma que existiam casos, quando os contenciosos fossem altamente perigosos para a segurança das tropas e funcionários das Nações Unidas, em que o uso da força seria necessário para cumprir o mandato aprovado pelo CS.

\section{RESPALDO JURÍDICO ÀS OPERAÇÕES DE MANUTENÇÃO DE PAZ}

A Carta das Nações Unidas não tem uma cláusula que se refira expressamente à existência e/ou normatização das operações de manutenção de paz. Sua origem data de um mecanismo utilizado pela ONU, com precedentes históricos na Liga das Nações, e que foi novamente retomado a partir da crise do Canal de Suez, em 1956, quando a organização decidiu criar um mecanismo para mediar e solucionar o conflito.

Podemos dizer que os princípios que norteiam as operações de manutenção de paz são oriundos das discussões para acordar as diretrizes da FENU I. Nesse contexto, a Assembléia Geral criou o Comitê Especial sobre Operações de Paz, o qual divulgou, em 1965, o "Relatório do Comitê Especial das Operações de Paz" (Apêndice de A/32/394 apud CARDOSO, 1998, p. 23), no qual ficaram definidos os princípios do consentimento das partes, da neutralidade, da imparcialidade e do uso limitado da força, exceto em casos de auto-defesa.

Decidir sobre o envio de operações de manutenção de paz é competência do CS e isso deve estar respaldado na justificativa da existência de ameaças à paz e à segurança internacionais. Tal procedimento foi adotado após a experiência da FENU I, pois discutir sobre o envio de operações de manutenção de paz na Assembléia Geral não mostrou ser um procedimento muito rápido diante da urgência com que as deliberações deveriam ser tomadas. 
A transferência dessa esfera de competência da Assembléia Geral para o CS também foi conseqüência da atribuição que a Carta da ONU dá ao CS para identificar o que representa ameaças à paz e à segurança internacionais:

O Conselho de Segurança poderá investigar sobre qualquer controvérsia ou situação suscetível de provocar atritos entre as Nações (...) a fim de determinar se a continuação de tal controvérsia ou situação pode constituir ameaça à manutenção da paz e da segurança internacionais (CARTA DAS NAÇÕES UNIDAS 1945, Capítulo VI, artigo 34).

A Carta da ONU também expressa que as decisões acatadas no CS devem ser cumpridas pelos demais Estados-membros:

A fim de assegurar pronta e eficaz ação por parte das Nações Unidas, seus Membros conferem ao Conselho de Segurança a principal responsabilidade na manutenção da paz e da segurança internacionais e concordam, no cumprimento dos deveres impostos por essa responsabilidade, o Conselho de Segurança aja em nome deles (CARTA DAS NAÇÕES UNIDAS 1945, artigo 24, parágrafo 1).

Dos trechos acima, podemos entender que a Carta das Nações Unidas delega ao CS a responsabilidade por identificar ameaças e deliberar como combatê-las. Está expresso no documento que a responsabilidade pela manutenção da paz e da segurança internacionais, bem como as medidas necessárias a serem implementadas, é fruto das decisões do órgão. Podemos concluir que as determinações do CS referentes à solução desse assunto são decisões políticas. Porém, não podem contradizer os objetivos da fundação da ONU materializados nas disposições da Carta.

O envio de operações de manutenção de paz está condicionado à interpretação do CS sobre o que representa ameaças à paz e à segurança internacionais. Percebemos nos trechos acima que no momento de constituição da ONU, em 1945, o CS tinha um papel fundamental: identificar quais seriam as ameaças à paz e à segurança internacionais e ser responsável por tomar decisões pertinentes à manutenção das mesmas. Tais recomendações e decisões deveriam ser respeitadas e executadas pelos demais órgãos da ONU e Estados-membros.

O primeiro trecho também evidencia que os conflitos vislumbrados pela ONU no momento de sua constituição, em 1945, previram somente contenciosos entre Estados. Entretanto, a emergência de alguns conflitos intra-estatais também se configurou como ameaça à paz e à segurança internacionais. Algumas dessas contendas ocorreram no período bipolar, mas foi a partir do fim desta ocasião que a ONU reconheceu que deveria estar mais atenta à emergência dos novos embates. 
Os documentos "Uma Agenda para a Paz" e "Suplemento de Uma Agenda para a Paz" são a formalização dos anseios da Secretaria Geral de que a ONU estivesse sintonizada com as novas ameaças do pós-Guerra Fria, principalmente com as "ameaças em potencial" nos conflitos intra-estatais. Assim, tal como o CS poderia "investigar" se o prolongamento de conflitos interestatais representava ameaça à paz e à segurança internacionais, compreendemos que essa atribuição se estendeu aos conflitos intra-estatais.

A Carta da ONU também prevê que, caso o CS julgue necessário, o recurso da força pode ser utilizado para cessar hostilidades entre nações ou impor a paz:

O Conselho de Segurança determinará a existência de qualquer ameaça à paz, ruptura da paz ou ato de agressão, e fará recomendações ou decidirá que medidas deverão ser tomadas (...) a fim de manter ou restabelecer a paz e a segurança internacionais (CARTA DAS NAÇÕES UNIDAS 1945, Capítulo VII, artigo 39, grifo nosso).

Neste sentido, a Carta das Nações Unidas exprime, no artigo 44, que o CS decidirá quando é necessário o emprego da força e sob quais condições é melhor fazêlo.

Percebemos que neste aspecto também houve extensão das responsabilidades inerentes ao CS em conflitos interestatais à resolução dos conflitos intra-estatais. $\mathrm{O}$ documento "Uma Agenda para a Paz" já mencionava a possibilidade de a ONU enviar operações de imposição de paz. Três anos depois, o "Suplemento de Uma Agenda para a Paz" enfatizou a hipótese de a ONU valer-se do uso da força em conflitos intraestatais de alto grau de periculosidade, como aqueles da Somália e da BósniaHerzegovina. Nessas circunstâncias, caberia ao CS determinar quando o uso da força deveria ser autorizado nos mandatos das operações de manutenção de paz.

$\mathrm{Na}$ Carta das Nações Unidas, os artigos 44 e 50 registram o caráter impositivo que as ações do CS podem adquirir para implementar a paz. Portanto, são também nesses artigos que localizamos a competência do CS em fazer uso da força para solucionar conflitos. Como tais artigos localizam-se no Capítulo VII da Carta, o CS convencionou discriminar que, quando uma operação de manutenção de paz estivesse autorizada a fazer uso da força, a operação seria aprovada mediante Capítulo VII.

\section{CONSIDERAÇÕES FINAIS}

Ao analisarmos as competências do CS como estão discriminadas nas disposições da Carta, percebemos que o órgão é o foro fundamental para as questões 
relacionadas à preservação da segurança internacional, pois cabe ao mesmo decidir como a ONU procederá na resolução de conflitos.

Entretanto, não podemos ignorar o fato de que entre os cinco membros permanentes estão aqueles que venceram a II Guerra Mundial. Essa condição deu-lhes o privilégio de construir a paz no novo concerto entre as nações. Os moldes em que essa paz foi estabelecida estiveram condicionados a não prejudicar ou interferir na defesa dos interesses estratégicos das principais potências militares mundiais. Vimos manifestações desses interesses no que conhecemos como "congelamento" do CS, quando Estados Unidos e União Soviética vetaram projetos de resoluções que não eram consensuais aos seus interesses durante a Guerra Fria.

Na transição para o período pós-Guerra Fria, o CS mostrou ser bastante dinâmico ao adaptar-se às mudanças e às novas atribuições que surgiram em decorrência do alargamento da agenda de segurança. Este fato também influenciou o aumento do envio de operações de manutenção de paz que foram, acima de tudo, um mecanismo da ONU para conter ameaças em potencial à preservação da paz e da segurança internacionais. Porém, devemos refinar nossa compreensão sobre o envio de operações de manutenção de paz.

Os critérios sobre o que se entende por ameaças à paz e à segurança internacionais estão em poder do CS, sobretudo, na capacidade decisória dos cinco membros permanentes. As aprovações do envio de operações de manutenção de paz do início da década de 1990 representaram o consenso entre as cinco potências militares mundiais, em que se decidia para qual conflito regional tropas deveriam ser enviadas, de acordo com as novas ameaças descritas em "Uma Agenda para a Paz" e em "Suplemento de Uma Agenda para a Paz".

Contudo, participar voluntariamente das operações de manutenção de paz implicou assumir gastos financeiros e riscos para os soldados dos Estados-membros participantes. Assim, o Estado-membro participante envia tropas, o que, em contrapartida, agrega à operação interesses além daqueles previstos pela ONU. Sobre isso, podemos citar o expressivo engajamento de tropas dos Estados Unidos em diversas operações de manutenção de paz no início dos anos 1990, norteado pela euforia da existência de um novo contexto internacional no qual prevaleceria o neoliberalismo e a democracia, os quais deveriam ser implementados em países onde esses padrões ainda não eram vigentes (PARIS, 2004, passim), como Haiti, Somália, Ruanda, entre outros.

Retomando a visão de Morgenthau sobre projeção de poder das potências, e resgatando o exemplo americano da Doutrina Clinton (1994), "Engajamento e 
Expansão"13, podemos inferir que as operações de manutenção de paz também se transformaram em possibilidades de projeção de poder para os Estados-membros participantes. Portanto, se de um lado a ONU estava preocupada em conter conflitos, para que os parâmetros da Carta e outros documentos das Nações Unidas fossem cumpridos, do outro estavam os Estados interessados em moldar-se a esse mecanismo para preservar, ou projetar, poder sobre outras regiões do mundo.

\section{REFERÊNCIAS BIBLIOGRÁFICAS}

ARON, R. Estudos Políticos. Brasília: Editora da Universidade de Brasília, 1985.

ARON, R. Paz e Guerra entre as Nações. São Paulo: Imprensa Oficial do Estado de São Paulo, 2002.

BOBROW, D. B.; BOYER, M. A. Maintaining System Stability: Contributions to Peacekeeping Operations. Journal of Conflict Resolution, Nova Iorque, v.41, n.6, pp. 723-748, dezembro, 1997.

BOUTROS-GHALI, B. Peacemaking and Peacekeeping for the New Century. DOYLE, $M$. Peacemaking and peacekeeping for the new century. Nova Iorque: Rowman \& Littlefield Publishers, 1998.

CARDOSO, A. J. S. O Brasil nas Operações de Paz das Nações Unidas. Brasília: Instituto Rio Branco: Fundação Alexandre Gusmão: Centro de Estudos Estratégicos, 1998.

CARTA DAS NAÇÕES UNIDAS, 1945. Disponível em: < http://www.onubrasil.org.br/documentos_carta.php>. Acesso em: 24/07/2010.

DEPARTAMENTO DE INFORMAÇÃO PÚBLICA. Basic Facts about the United Nations. Nova Iorque: ONU, 1995.

DOYLE, M. W. 1998. Discovering the Limits and Potential of Peacekeeping. OTUNNU, O. A.; DOYLE, M. W. Peacemaking and peacekeeping for the new century. Nova Iorque: Rowman \& Littlefield Publishers, 1998.

DPKO. Lista de Operações de Manutenção de Paz do Departamento de Operações de Manutenção de Paz das Nações Unidas. Disponível em: < http://www.un.org/en/peacekeeping/>. Acesso em: 24/07/2010.

FONTOURA, P. R. C. T. O Brasil e as Operações de Manutenção da Paz das Nações Unidas. Brasília: Instituto Rio Branco: Fundação Alexandre Gusmão: Centro de Estudos Estratégicos, 1999.

FRANCO, A. Armed Nonstate Actors. MALONE, D. Decision-making in the UN Security Council: the case of Haiti 1990-1997. Nova Iorque: Oxford.

MEARSHEIMER, J. The false promise of International Institutions. In: Theories of War and Peace: an international security reader. Cambridge: MIT Press, 2000.

13 "Uma Estratégia Nacional de Segurança de Engajamento e Expansão" está disponível em: <http://www.au.af.mil/au/awc/awcgate/nss/nss-95.pdf>. Acesso em 13/11/2010. 
MORGENTHAU, H. J. A política entre as nações: a luta pela guerra e pela paz. Brasília: Editora Universidade de Brasília/ Instituto de Pesquisa de Relações Internacionais. São Paulo: Imprensa Oficial do Estado de São Paulo, 2003.

NOGUEIRA, J. P. e MESSARI, N. Teoria das Relações Internacionais: correntes e debates. Rio de Janeiro: Elsevier, 2005.

PARIS, R. Broadening the Study of Peace Operations. International Studies Review, v.2, n.3, p.27-44, 2000. Disponível em:

$<$ http://aix1.uottawa.ca/ rparis/isre23-2-Paris.pdf>. Acesso em: 13/11/2010. Cambridge Press.

2004. At war's end: building peace after civil conflict. Nova Iorque:

SUPLEMENTO DE UMA AGENDA PARA A PAZ. 1995. Disponível em: <http://www.un.org/Docs/SG/agsupp.html>. Acesso em 24/07/2010.

UMA AGENDA PARA A PAZ. 1992. Disponível em:

<http://www.un.org/Docs/SG/agpeace.html>. Acesso em 24/07/2010.

UMA ESTRATÉGIA NACIONAL DE ENGAJAMENTO E EXPANSÃO. 1994. Disponível em: <http://www.au.af.mil/au/awc/awcgate/nss/nss-95.pdf > . Acesso em 13/11/2010.

UNCETA, José Antonio Perea. 1995. Las nuevas características de las operaciones de cascos azules de las Naciones Unidas. Disponível em: < http://www.rcumariacristina.com/ficheros/04\%20Jose\%20Antonio\%20Perea.pdf>. Acesso em: 24/07/2010. 